\title{
Ciudadanía imaginada y presupuesto participativo en los pueblos indígenas de la Selva Central del Perú
}

\section{Imagined citizenship participative budget in the indigenous peoples of the Central Jungle of Peru}

Luis Calcina Romero - Mestre em Sociología pela Universidad Nacional Mayor de San Marcos. Mestrando em Dinâmicas Territoriais e Sociedades na Amazônia pela UNIFESSPA. Graduado em Ciencias de la Comunicación pela Universidad Alas Peruanas y Universidad Nacional del Centro del Perú. E-mail: luisguet@hotmail.com

William Santos de Assis - Professor da Universidade Federal do Pará atuando no PPGAA/ UFPA e no PDTSA/UNIFESSPA. Mestre em Agriculturas Familiares e Desenvolvimento pela UFPA e Doutor em Ciências pelo CPDA/UFRRJ. E-mail: williamassis@ufpa.br

\section{Resumo}

En este trabajo reflexionamos sobre la relación entre el presupuesto participativo y el ejercicio de la ciudadanía en los pueblos indígenas. El objetivo es analizar la configuración de una ciudadanía imaginada en el marco del presupuesto participativo de tres distritos de la Selva Central peruana. A través de un estudio exploratorio los primeros resultados revelan que en contextos diferenciados que configuran una zona de contacto, el presupuesto participativo no es un escenario neutral, porque el peso de las decisiones recae en los grupos de colonosmigrantes que ejercen dominio y hegemonía local. En este contexto la participación de los pueblos indígenas no es relevante, son sujetos de discriminación y difícilmente son escuchados, configurándose de esta manera una ciudanía imaginada, que es tal porque no visibilizan el poder que se ejerce sobre ellos y se asumen a sí mismos incorporados, escuchados $\mathrm{y}$ atendidos, sin percibir que crean una falsa percepción de inclusión.

\section{Palavras-chave}

Presupuesto participativo. Ciudadanía imaginada. Pueblos indígenas. Selva Central.

\begin{abstract}
In this paper, we reflect about the relationship between the participative budget and the citizenship exercise of the indigenous peoples. The aim is to analyze the configuration of imagined citizenship under the participatory budget in three districts of the Peruvian Central Jungle. Through an exploratory study the first results reveal that in differentiated contexts that form a zone of contact, the participatory budgeting is not a neutral scenario, because the weight of the decisions relapse into the groups of colonist-migrants who exercise domain, and local hegemony. In this context the participation of indigenous peoples is not relevant, they are subjects of discrimination and difficultly they are listened, configuring in this way an imagined citizenship, which is such because they not make visible the power exerted on them and they imagine incorporated, listened to and cared for, without perceiving that create a false perception of inclusion.
\end{abstract}

\section{Keywords}

Participative budget. Imagined citizenship. Indigenous peoples. Central Jungle. 


\section{INTRODUCCIÓN}

El concepto de ciudadanía motiva diversas reflexiones sobre el rol de los individuos como actores de un proceso social y su relación con el Estado. El Estado es un campo de lucha y las relaciones que se establecen con él dependerán de cómo el individuo asume esta lucha, de confrontación si se constituye en clase social o incorporación y/o espectador si se asume como ciudadano. En nuestra perspectiva la categoría de clase social ha perdido protagonismo en aras del fortalecimiento ciudadano. Esta categoría, sin embargo, es problemática en la medida que se invisibilizan las diferencias. En esta relación ciudadanía-Estado se establecen una serie de conflictos y negociaciones que solo son visibles a partir de un análisis más exhaustivo. El ejercicio de la ciudadanía es posible solo si se confronta con estructuras que buscan limitarla, como el Estado, que en muchos casos opera sin tomar en cuenta las diferencias sociales y culturales existentes.

Si a esta compleja relación le agregamos la variable indígena entonces podemos darnos cuenta que la construcción del Estado nacional liberal no se efectuó sobre principios ciudadanos de libertad o igualdad, sino sobre concepciones hegemónicas de poder y dominio. Esto se hace evidente cuando se implementan políticas públicas en contextos multiculturales, como es el caso del presupuesto participativo. Esta política pública en su creación se concibe como un espacio neutral que puede ser apropiado por el ciudadano, sin observar que es además un escenario de lucha simbólica y de pugna por el poder entre grupos locales, donde los pueblos indígenas se encuentran en situación de desventaja.

El interés de considerar la relación existente entre el presupuesto participativo y el ejercicio de la ciudadanía indígena como objeto de estudio nace a partir de las primeras observaciones realizadas en los presupuestos participativos implementados en la Selva Central peruana. En un primer momento se encontró que este espacio destinado a construir ciudadanía, por la forma como es implementado, promueve una falsa percepción de inclusión. Se observa también que los grupos hegemónicos locales, al contar con mayores herramientas y capacidades, se apropian de este instrumento para ejercer dominio y hegemonía sobre los grupos subalternos. Estas observaciones nos llevan a afirmar que el presupuesto participativo construye en los pueblos indígenas una ciudadanía imaginada.

Por esa razón el objetivo de esta reflexión es analizar y explicitar la configuración de esta ciudadanía imaginada en los pueblos indígenas a partir del presupuesto participativo implementado en tres distritos de la Selva Central del Perú. Este escenario geográfico es una de las zonas donde el conflicto cultural 
se hace evidente cuando se habla de procesos de participación y ejercicio de ciudadanía. Por un lado, con mayor peso político, se ubican los colonos o grupos de migrantes y sus descendientes y por el otro, en una posición de subordinación ciudadana, se ubican los grupos indígenas que, a pesar de su condición de marginación, participan y demandan mayores beneficios para sus comunidades.

Es una tarea complicada intentar establecer un marco teórico adecuado que dé cuenta de la relación política pública-ciudadanía. Sin embargo, es importante destacar los aportes sobre Estado-clase de Poulantzas (1977), el enfoque de dominación y legitimación de Weber y la concepción de hegemonía de Gramsci (1980). Partiendo de estos presupuestos teóricos se muestra la transformación de la clase social en ciudadanía traducida en nuevas formas de resistencia frente al estado capitalista moderno.

Desde esta perspectiva analizaremos las formas de ejercicio ciudadano a partir de las demandas políticas por mayores derechos (MOUFFE, 1987), de la ciudadanía multicultural (KYMLICKA, 1996), es decir aquella que se construye según las particularidades propias de un contexto multicultural, y de las ciudadanías diferenciadas (YOUNG, 2006). También se consideran aspectos antropológicos como las formas de práctica democrática en la población indígena (GASCHÉ, 2011). Tales textos ayudan a comprender cómo se entiende y construye la ciudadanía en las sociedades comunitarias. Además, tomaremos elementos teóricos sobre participación oriundos de los análisis realizados por Franco (1984) sobre los entornos favorables en la construcción de una ciudadanía participativa.

Finalmente, recogiendo los postulados de Anderson (1991) sobre la nación como una comunidad imaginada, construimos un referente teórico de ciudadanía imaginada como una forma de ejercicio ciudadano artificial e insustancial que alimenta la creciente preocupación de incorporación de los pueblos indígenas en las estructuras formales de toma de decisiones en el nivel local.

\section{LA SELVA CENTRAL Y EL PRESUPUESTO PARTICIPATIVO}

La Selva Central está ubicada dentro de los trópicos húmedos americanos y es caracterizada por suelos ácidos y estériles ${ }^{1}$. Geográficamente se ubica entre los paralelos 8' y 13' de latitud sur y los meridianos 71' y 76' longitud oeste. Es parte de la provincia biogeográfica Yungas, contiene 11 zonas de vida o ecosistemas

Compuesto por oxisoles y ulisoles que se caracterizan por su "alta acidez, niveles tóxicos de aluminio, deficiencias en fósforo, calcio, magnesio, azufre, zinc y otros micronutrientes, baja capacidad de intercambio catiónico, y alta capacidad de fijación de fósforo". En: "Estudio de Casos de Manejo Ambiental: desarrollo integrado de un Área en los Trópicos Húmedos - Selva Central. 
y posee una red de cadenas montañosas que van desde los 600 hasta los 4.832 m.s.n.m. ${ }^{2}$ La temperatura, sin considerar las zonas de mayor altura, oscila entre $19^{\circ}$ y $28^{\circ} \mathrm{C}$, y posee una precipitación anual de 2.000 a $4.000 \mathrm{~mm}$. Se localiza en la parte central del Perú y comprende ocho departamentos, con una extensión total de 16 millones de hectáreas, equivalente a $160.000 \mathrm{Km}^{2}$.

En esta región amazónica predominaron los pueblos indígenas pertenecientes al grupo lingüístico Arawak, conocido también como Arahuaco, que son además parte del sub grupo preandino o Arawak preandino (RIVET; TIVESTIN, 1940, citado por GOW, 2002, p. 150) y, en menor medida, es posible ubicar etnias de las familias lingüísticas Pano. Diversos estudios, fundamentalmente de tipo antropológico (VARESSE, 1969; SMITH, 1974) o económico (BARCLAY; SANTOS-GRANERO, 1980), identifican a la Selva Central con un continuo histórico, político, económico y cultural, bajo dominio del grupo Arawak, relegados por los grupos de colonos migrantes que llegaron después.

De tal manera, la geografía de esta región queda definida por los pueblos ashaninka, yanesha y nomatsiguenga, seguido por los matsiguengas y amahuacas y, en menor medida, por los Piro y Culina (Tabla 1). Renard y Casevitz (1996) proponen una distribución geográfica del grupo lingüístico Arawak, según se muestra en el gráfico siguiente:

Figura 1 - Distribución geográfica del grupo lingüístico Arawak en la Selva Central

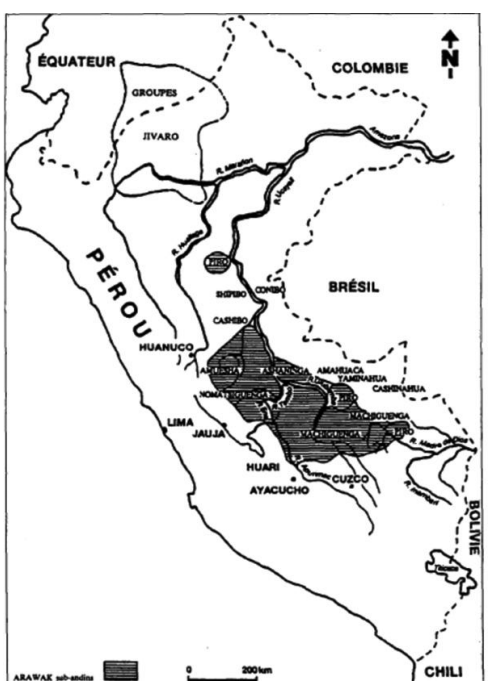

Fuente: Mapa elaborado por France-Marie Renard-Casevitz, publicado en REDIAL, 1995-1996. Nº 6-7, p. 148-213.

2 Zona de mayor altitud que corresponde al nevado Bateacocha. 
Tabla 1 - Comunidades censadas por pueblo indígena y por departamento en la Selva Central

\begin{tabular}{|c|c|c|c|c|c|c|c|c|c|c|}
\hline 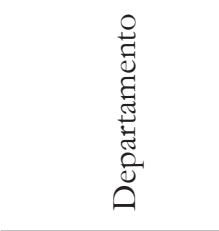 & $\begin{array}{l}\bar{\pi} \\
0 \\
0 \\
0 \\
: 0 \\
0 \\
0 \\
0 \\
0 \\
0 \\
0\end{array}$ & $\begin{array}{l}\dot{\Xi} \\
\text { छ् } \\
\dot{0} \\
\circ \\
\dot{Z}\end{array}$ & 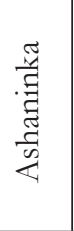 & 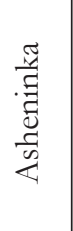 & 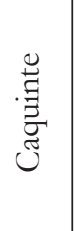 & 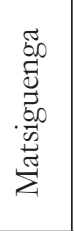 & 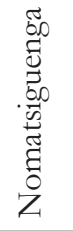 & $\stackrel{0}{0}$ & 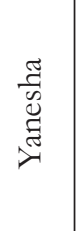 & $\underset{H}{\stackrel{H}{5}}$ \\
\hline Ayacucho & 231 & 4 & 4 & & & & & & & 4 \\
\hline Cusco & 15230 & 65 & 31 & & & 32 & & 2 & & 65 \\
\hline Huánuco & 2594 & 13 & 6 & & & & & & 7 & 13 \\
\hline Junín & 73637 & 238 & 209 & & 2 & & 22 & & 5 & 238 \\
\hline Pasco & 16414 & 113 & 83 & & & & & & 30 & 113 \\
\hline Ucayali* & 40407 & 136 & 77 & 49 & & 3 & & 7 & & 136 \\
\hline Loreto & & 3 & 1 & & & & & 2 & & 3 \\
\hline Madre de Dios & & 11 & & & & 5 & & 6 & & 11 \\
\hline TOTAL & 148513 & 583 & 411 & 49 & 2 & 40 & 22 & 17 & 42 & 583 \\
\hline
\end{tabular}

Fuente: elaboración propia con datos de Instituto Nacional de Estadística (2008)

El ámbito geográfico de la Selva Central es amplio y diverso, no solo por la demarcación política sino también por la diversidad social existente. Los pueblos indígenas autodefinidos como "guerreros" les permitieron mantener una posición beligerante desde tiempos coloniales, siendo su máxima expresión la rebelión de 1742, liderada por Juan Santos Atahualpa, que mantuvo al margen de su territorio a la colonia española y hacendados de la época por más de 100 años.

Con el advenimiento de la República, por acción del Estado criollo ${ }^{3}$, la lógica expansionista de los caudillos militares y la expansión comercial de los grupos de hacendados de la sierra (principalmente de las zonas de Tarma y Huánuco) se inició un agresivo proceso de reconquista de los territorios indígenas de la Selva Central (SANTOS; BARCLAY, 1980) a través del ingreso de migrantes europeos (franceses, italianos y alemanes) para la explotación de los recursos, los que luego serían desplazados por la ocupación desordenada de migrantes de la sierra andina ${ }^{4}$ de Tarma, Jauja y Huancayo principalmente. Estos se asentaron y se posicionaron como el grupo hegemónico local (aunque disperso en su origen) hasta convertirse en el sector mayoritario $(90 \%)$ de la población.

La forma de ocupación que ejercieron estos grupos de migrantes, según lo entiende Santos y Barclay (1980, p. 30), se da en dos dimensiones: la primera es

3 En la historiografía peruana se denomina Estado criollo al Estado controlado por los grupos criollos que eran los descendientes de españoles pero nacidos en suelo americano.

4 Generalmente indígenas de la sierra y mestizos. 
la dimensión físico-geográfica, que es la ocupación física del territorio a través de la ocupación humana, la transformación del ambiente con fines productivos y el establecimiento de redes de comunicación; la segunda es la dimensión ideológicojurídica, que se da a través de la apropiación ideológica y la apropiación del espacio a través de la palabra con la domesticación y renombramiento de diversos espacios ya anteriormente ocupados.

Por la forma como se dio esta ocupación podemos afirmar que la Selva Central se constituye como una zona de contacto. Por zona de contacto Pratt (1996, p. 3) entiende los:

lugares en los que confluyen o entran en comunicación culturas que han seguido históricamente trayectorias separadas y establecen una sociedad, con frecuencia en el contexto de una relación de colonialismo.

En otras palabras, una zona de contacto es un espacio de coexistencia multicultural que se origina a partir de la invasión y la violencia que luego se constituyen en relaciones de desigualdad y se establecen en una relación de dominación; es, por lo tanto, un escenario artificial que da sentido a la materialización de la ciudadanía imaginada. Ahora bien, toda relación de dominación implica una alteridad, por lo cual es factible que se presente una permanente lucha por el poder interpretativo y la producción de significados (PRATT, 1996; FRANCO, 1984).

Las consecuencias de este tipo de ocupación configuran un escenario complejo y difícil. En el departamento de Junín, donde se registra el mayor número de comunidades nativas (236 comunidades), $74.6 \%$ de ellas no cuenta con servicio de alumbrado eléctrico, $22 \%$ no tiene centros educativos, $77.7 \%$ no cuenta con establecimientos de salud dentro de la comunidad y los que existen son generalmente botiquines comunales. En términos departamentales Junín presenta una desnutrición crónica infantil de 22,1\% y desnutrición aguda de 1,0\%, además de altos índices de anemia infantil (51,6\%).

En este escenario observamos que la población colona migrante, como grupo local dominante, tiene el control de las decisiones políticas y económicas del distrito así como del circuito comercial de los productos agropecuarios, por lo que la población indígena depende de ellos para acceder a los mercados. En este espacio socialmente asimétrico se implementa el presupuesto participativo ${ }^{5}$.

\footnotetext{
Aunque la Ley de Bases de la Descentralización, Ley Nº 27783 del año 2002 y la Ley Orgánica de Municipalidades, Ley N 27279 del año 2003, señalan mecanismos de participación ciudadana en la gestión local, no es sino con la Ley Marco del Presupuesto Participativo, Ley N ${ }^{\circ}$ 28056, que este mecanismo de participación se institucionaliza.
} 
Las construcciones teóricas sobre el presupuesto participativo abonan en favor de una imagen positiva del mismo como herramienta participativa, de ahí que se entienda como un instrumento de política y de gestión donde concertadamente autoridades y población deciden en qué y cómo se invertirán los recursos del Estado. La Ley Marco del Presupuesto Participativo sostiene que es la "asignación equitativa, racional, eficiente, eficaz y transparente de los recursos públicos, que fortalece las relaciones Estado - Sociedad Civil”. Por su parte, Lieberher (2003), tomando el concepto de De Souza, considera que el presupuesto participativo es ante todo un proceso democrático "voluntario y universal" que permite a la población discutir sobre el presupuesto y sobre las políticas públicas,

El mecanismo de funcionamiento establecido en la Ley establece cuatro fases, esquematizadas en la siguiente figura:

Figura 2 - Fases del proceso de presupuesto participativo basado en resultados

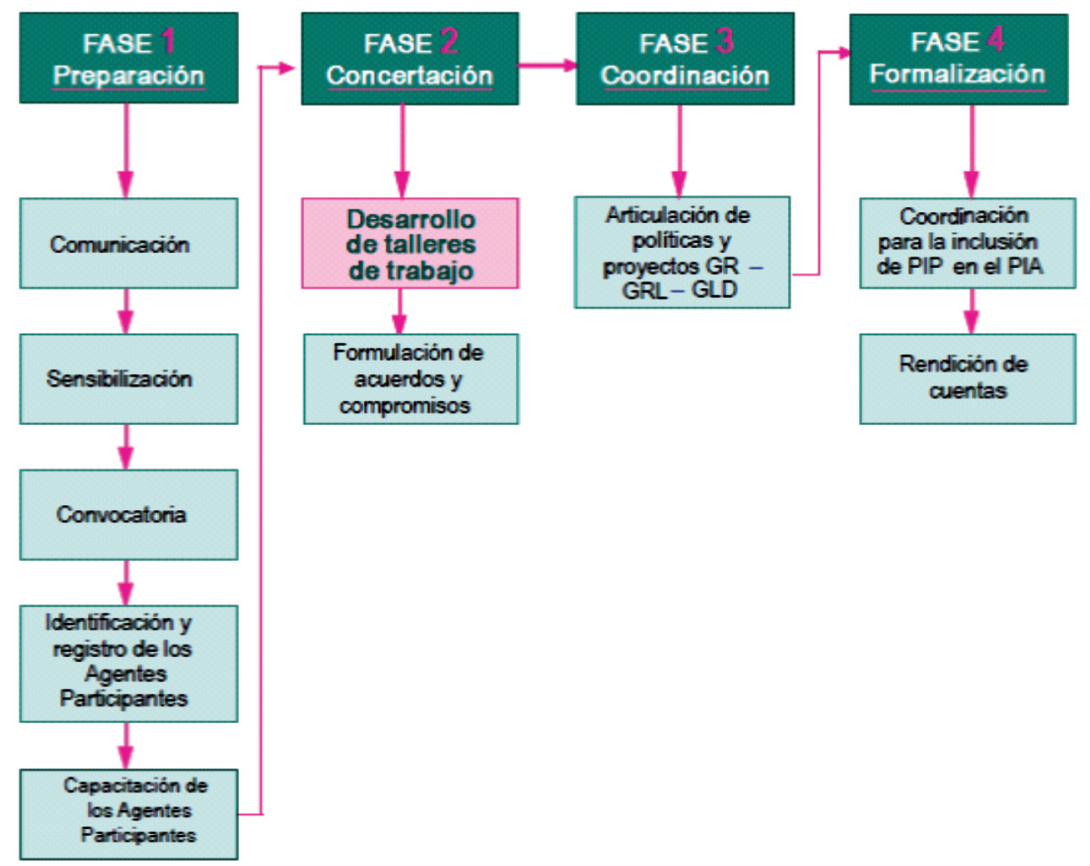

Fuente: Guía del Presupuesto Participativo Basado en Resultados, PRODES, 2010, p. 22

La primera fase requiere la constitución de agentes participantes, que son los grupos de ciudadanos organizados que participan en el proceso y, por basarse en el mecanismo de representación, no permite la participación individual. La convocatoria se realiza a través de medios de comunicación, generalmente de 
poco alcance, y de invitaciones a diversas organizaciones sociales. La segunda fase es la etapa de la confrontación simbólica y de poder; en esta etapa se proponen, discuten y deciden los proyectos a aprobarse. La tercera y cuarta fases son las etapas de consumación del proceso. Aquí se firman las actas que aprueban las obras priorizadas. Concluido el proceso, un comité técnico designado para tal fin opera como filtro y es en última instancia el que decide, en función de los criterios de evaluación establecidos, qué obras serán ejecutadas.

Visto desde esta perspectiva el presupuesto participativo se convierte en la instancia más importante para planificar de manera participativa y concertada el presupuesto de una municipalidad. En este espacio se discuten las obras a ejecutarse en salud, educación, actividades productivas, ambiente, pueblos indígenas, entre otros. No obstante su finalidad, el presupuesto participativo no es considerado una instancia de planificación de la gestión. Prueba de ello es que los recursos que se asignan para "planificar" el desarrollo local resultan siempre insuficientes. El caso de la municipalidad distrital de Perené es ilustrativo al respecto. Su presupuesto se incrementó aproximadamente de 3 a 10 millones de soles anuales entre 2009 y 2014. En este mismo período el monto asignado al presupuesto participativo pasó de 400 mil soles a un poco más de 1 millón de soles al año, es decir, no más de 13\% del total del presupuesto municipal.

\section{HEGEMONÍA, DOMINACIÓN Y CIUDADANÍA}

La Selva Central, al atravesar por procesos de ocupación, se constituyó en una zona de contacto que configuró grupos hegemónicos y de dominio. El Estado, sintonizado con esta racionalidad, apoyó e impulsó políticas de colonización sin considerar los impactos generados en la población indígena. Esta misma lógica operó al implementar el presupuesto participativo. Allí el Estado construye relaciones hegemónicas en relación con sus ciudadanos, por lo que bien puede ser entendido como un campo de lucha. Poulantzas (1977, p. 43) señala que el Estado es una "estrutura na qual se condemsam as contradições entre os diversos níveis de uma formação".

Ahora bien, todas las relaciones comunitarias están basadas en relaciones de dominación. La dominación es, dice Weber (2002), una forma de poder que busca "imponer la voluntad propia sobre la conducta ajena" y su finalidad última es una determinada "voluntad manifiesta" del dominador sobre las acciones de otros (dominados), logrando la obediencia. El rasgo distintivo de esta obediencia es que se realiza "como si los dominados hubieran adoptado por sí mismos y como máxima de su obrar el contenido del mandato" (WEBER, 2002, 
p. 699). Si hablamos de un régimen de gobierno y, por lo tanto, de la función del Estado, esta forma de dominación se ejerce, por un lado, a través de las estructuras burocráticas que naturalizan las relaciones de dominación revestidas de "un servicio" otorgado del dominador al dominado y, por otro, a través del monopolio de la violencia legítima.

De esta manera, los espacios de lucha local por el poder, expresados en las políticas de Estado (como el presupuesto participativo), no se ven como ejercicio de dominación sino como prácticas políticas regulares y naturales. Esto es posible porque en estos espacios las relaciones de dominación, sobre todo la dominación burocrática, se naturaliza y se asume como parte del proceso regular de la democracia pluralista; aquí se produce una obediencia no a la persona, sino a la regla y esto solo es posible por la ausencia de reflexión del espíritu de la norma. Esto es particularmente importante en niveles descentralizados del Estado donde el dominio burocrático nacional, al ser difuso, es asumido por la burocracia local con características similares. Pero los grupos que detentan este dominio son sustancialmente diferentes y hasta se confrontan con el poder nacional.

El concepto de hegemonía trabajado por Gramsci (1980) es otro elemento que ayuda a comprender mejor cómo se da el proceso de dominación en diferentes subniveles del Estado. Para este autor la hegemonía es una forma de aceptación del poder y de la dominación de manera voluntaria, donde se invisibiliza la coerción y la violencia. Esta forma de aceptación de la dominación es voluntaria, o por lo menos es así como se representa y se asume. De esta manera, los espacios de lucha local por el poder, expresados en las políticas públicas (como el presupuesto participativo), no se ven como ejercicio de dominación sino como prácticas políticas regulares y naturales.

La hegemonía solo es posible a partir de la lucha ideológica y se efectiviza al tomar en cuenta "los intereses y tendencias de los grupos sobre los cuales ejercerá la hegemonía” (GRAMSCI, citado por MOUFFE, 2000, p. 190). Gramsci entendía que la hegemonía no era coerción; por el contrario:

En el sistema hegemónico existe democracia entre el grupo dirigente y los grupos dirigidos en la medida en que el desarrollo de la economía y por consiguiente de la legislación que expresa tal desarrollo, favorece el pasaje (molecular) de los grupos dirigidos al grupo dirigente. (GRAMSCI, 1980, p. 196).

Este beneficio que se ofrece de dirigentes a dirigidos no es gratuito y tiene como objetivo la perpetuación del Estado-clase y el control del aparato del Estado y de los modos de producción por parte de los grupos dominantes. Las relaciones hegemónicas así expresadas por el poder institucionalizado se 
reproducen a niveles micro y los grupos hegemónicos locales ejercen dominio sobre los grupos subalternos -entiéndase indígenas- relegándolos a un papel marginal. Esto representa un primer indicio en la configuración de la ciudadanía imaginada. La dominación se realiza a través de la entronización de valores y visión del mundo donde la educación, la religión y la cultura juegan un rol determinante.

Gramsci limitó su análisis a estructuras macro políticas y formuló la necesidad de construir proyectos hegemónicos alternativos (contrahegemónicos) que llevarían al poder a los grupos subalternos, donde la dimensión cultural tenía un rol fundamental. En un contexto de democracia pluralista liberal es probable que esta forma de resistencia tenga ciertas limitaciones dado que las condiciones propias de los grupos subalternos, en este caso de los pueblos indígenas, no permiten pensar en lo inmediato en soluciones contrahegemónicas.

La salida a esta imprecisión nos la proporciona Mouffe (1987). Para esta autora pensar en hegemonía es pensar en las nuevas formas de estructuración social propias del capitalismo tardío. La salida que se debe esgrimir es la radicalización de la democracia, entendida como "articulación de las luchas contra las diferentes formas de subordinación" (MOUFFE, 1987, p. 6). Desde esta perspectiva el concepto hegemonía no se expresa solo en relaciones políticas de dominación sino que está presente también una lógica social.

Así, la tarea pendiente no consiste en "renegar de la ideología liberaldemocrática sino al contrario, en profundizarla y expandirla en la dirección de una democracia radicalizada y plural” (MOUFFE, 1987, p. 199). Esta radicalización de la democracia implica extender las luchas sociales (articulación de antagonismos), entendida como proporcionar a los sujetos una serie de herramientas que les permitan participar en la toma de decisiones. A partir de esta lógica democrática es posible romper con cualquier proyecto hegemónico que, como veremos, fue utilizado por los movimientos indígenas en sus demandas y adquisición de nuevos derechos.

Los presupuestos teóricos aquí analizados nos permiten comprender que en toda relación social existe una relación de dominación y obediencia que es estructurada desde el poder central del Estado. El ejercicio de este poder genera una hegemonía que es invisibilizada, por lo que termina siendo aceptada de manera voluntaria y transmitida a través de canales formales como la escuela, los medios de comunicación, la religión o la cultura. Pero la hegemonía no implica una relación paritaria que enfrenta la sociedad al Estado, puesto que la complejidad social permite visibilizar diversos intereses en lucha. La salida de este estado de domesticación social a partir de la diversidad social existente solo 
es posible si se logran articular los diferentes intereses, proporcionándoles las herramientas para radicalizar la democracia y hacerla más participativa, lo que implica desarrollar con mayor intensidad la dimensión ciudadana.

\section{DE LA CIUDADANÍA ENTRE IGUALES A LA CIUDADANÍA INDÍGENA}

La idea de ciudadanía va a depender del enfoque de análisis. López (1997) considera que la evolución del concepto, luego de los postulados iniciales de Marshall, va a pasar por una discusión entre liberales y comunitaristas, que luego derivaría en una discusión entre ciudadanía activa y ciudadanías diferenciadas. En efecto, el primer teórico que entendió la ciudadanía como una continuación de las clases sociales fue Marshall (1949), para quien la ciudadanía se entiende como la pertenencia plena a una comunidad que compuesta de tres tipos: civil, política y social. La ciudadanía civil permitió la consolidación de los derechos fundamentales como libertad, autonomía, derechos de propiedad, organización y justicia. La ciudadanía política implica la incorporación de grupos pobres y excluidos en las decisiones políticas y la ciudadanía social significa el derecho a desarrollo e igualdad social, siendo ésta última el punto culminante en este tránsito de clase social a ciudadanía.

El postulado de Marshall concibe los derechos adquiridos entre iguales pero no asume la diferencia como parte constitutiva de una sociedad. La posterior discusión entre liberales y comunitaristas intentó responder sin éxito esta cuestión. La perspectiva de la ciudadanía liberal asume que los individuos son sujetos de derechos y con capacidad de libre elección. Su incorporación a la sociedad es individual y en cooperación con otros individuos. La perspectiva de la ciudadanía comunitaria, por su parte, considera que la capacidad de elegir del individuo solo es posible en un entorno social por lo que "la imagen individualista de la persona es ontológicamente falsa” (LOPEZ, 1997, p. 96).

Aunque el problema de la diferenciación es tangencialmente analizado, principalmente desde la perspectiva de la ciudadanía activa (equilibrio entre derechos y deberes), el problema fue resuelto inicialmente por Kymlicka (1996), quien reconoce la existencia de derechos diferenciados y establece que "los miembros de determinados grupos se incorporan a la comunidad política no solo en calidad de individuos, sino también a través del grupo" (KYMLICKA, 1996, p. 240).

Kymlicka sostiene que en estados multiétnicos existen tres formas de derechos que son aplicables a los grupos diferenciados: el primero es el derecho 
al autogobierno y autodeterminación, el segundo se refiere a los derechos poliétnicos, como derechos que ayudan a que expresen sus particularidades culturales, y el tercero se entiende como derechos especiales de representación basados en la discriminación positiva. La obtención de estos derechos no configura una sociedad más equitativa e igualitaria, principalmente porque el discurso de ciudadanía no rompe con las estructuras hegemónicas de dominación ni modifica los grupos que lo controlan. De hecho ayuda a visibilizar las particularidades culturales, pero los grupos diferenciados deben disputar espacios de poder en condiciones de desventaja.

Young (2000), basado en el concepto de ciudadanía diferenciada, intenta superar esta dificultad sosteniendo que la incorporación de los grupos minoritarios pasa también por la implementación de cuotas de representación que garantice la defensa de sus intereses. De alguna manera Jung apuesta por modificaciones más sustanciales en la sociedad liberal para hacerla más justa, a través de la incorporación de la diferencia. A pesar de los esfuerzos teóricos por imaginar una sociedad más equitativa en contextos multiculturales, las demandas de ciudadanía de los grupos indígenas, por ejemplo, son cada vez más fuertes y apuntan a una reestructuración del Estado y de todos sus componentes.

A este nuevo proceso que implica una visión etnopolítica de la etnicidad se le conoce como ciudadanía étnica o ciudadanía indígena y su propuesta está sustentada: a) en mayor autonomía y una construcción del Estado con carácter plurinacional; b) derechos de representación y participación política; y c) derecho al respeto cultural y la tolerancia (GARZÓN, 2012). Al respecto Garzón sostiene que

La ciudadanía étnica se constituye en un sincretismo basado en la etnicidad, la identidad y la acción colectiva de los pueblos indígenas en su lucha por erradicar las injustas relaciones de poder en aras de una sociedad más democrática, participativa y equitativa. (Garzón, 2012, p. 194-195).

Desde nuestra perspectiva, esta ciudadanía étnica reclama el derecho de decidir sobre su territorio, recursos naturales, sistemas educativos, lengua y demandas de autonomía que trascienden el Estado oficial ${ }^{6}$, es decir, no son demandas y acciones destinadas a luchar contra un modelo económico, sino contra un modelo civilizatorio. La perspectiva que nos proporciona este enfoque de la ciudadanía indígena pone en cuestión el todo social construido hasta el momento. La visión utópica de esta mirada y el desborde de expectativas nos lleva a aterrizar el concepto de lo que entendemos por ciudadanía indígena. En principio esta ciudadanía está basada, como lo afirmamos arriba, en el derecho

6 La conformación del Primer Gobierno Autónomo Indígena del Perú por el pueblo Wampis, el año 2015, va en este sentido. 
a la participación y representación, el derecho a la autonomía y autogobierno pero también en la necesidad de incorporación al contexto social donde se desenvuelven.

El juego de esta nueva concepción de ciudadanía indígena radica en que se desplaza indistintamente entre la ciudadanía liberal individual y la ciudadanía colectiva y recrea formas de organización ancestral para el ejercicio de sus derechos. De esta manera la dualidad que sustentamos en las prácticas de ciudadanía indígena se sustenta, por ejemplo, para el caso del principio de autoridad, en la experiencia y dominio de los recursos de la naturaleza (modelo de representación ancestral) y de la capacidad del líder de desplazarse entre la aldea y la sociedad oficial (modelo de representación moderno).

En la ciudadanía indígena los niveles de decisiones son altamente deliberativos y generalmente consensuados pero las emplean en formas de organización impuestas por la sociedad oficial ${ }^{7}$. Cuando necesitan ser atendidos en sus demandas la ciudadanía adquiere una forma militar, basada en un comando central y en un líder con cuya autoridad se puede disentir pero no se cuestiona. En el mismo sentido recrean la democracia, a lo que Gasché (2010) llama democracia activa, con los principios de:

libertad y autonomía personales y domésticas, la reciprocidad - positiva y negativa - y la solidaridad, la aspiración a la igualdad social y material, la generosidad y el consumo suntuario, así como en el respeto de una autoridad basada en el saber y saber-hacer. (GASCHÉ, 2010, Tomo II, p. 170).

El análisis realizado hasta el momento nos permite entender que la ciudadanía, liberal o comunitarista, vista como sentido de pertenencia e inclusión en una sociedad de iguales invisibiliza a los grupos minoritarios y no les proporciona las herramientas para su incorporación como ciudadanos. Esta deficiencia ha sido superada en parte por las concepciones de ciudadanía multicultural y ciudadanía diferenciada que abogan por dotar de mayores derechos a los pueblos indígenas, tomando en cuenta sus particularidades culturales.

Desde la perspectiva de ciudadanía indígena estos derechos adquiridos no son suficientes ya que los pueblos indígenas demandan cada vez mayores niveles de autonomía y decisión, inclusive al margen del Estado. Estas exigencias apuestan por una reconfiguración del Estado y la sociedad liberal individual nacional por un estado plurinacional colectivista que incorpore practicas ciudadanas tradicionales, basada en el respeto por la libertad, autonomía, reciprocidad y solidaridad.

\footnotetext{
La asamblea comunal es la forma más común en la toma de decisiones. Este modelo organizativo se impuso a través de la legislación peruana.
} 


\section{EL GIRO A LA CIUDADANÍA IMAGINADA}

El ideal expresado en la ciudadanía indígena implica desde diversas perspectivas un imposible social por la forma como se ha construido los imaginarios colectivos que, como vimos, se sustenta en criterios de pertenencia a una comunidad de iguales. Esto da espacio para teorizar lo que venimos sosteniendo como ciudadanía imaginada. Algunos autores como López (1997) entiende por ciudadanía imaginada una concepción de ciudadanía posible, imaginada teóricamente, pero sin correlato en la realidad. Al respecto afirma:

En este sentido convendría distinguir los tipos de ciudadanía de las concepciones de ciudadanía. Los primeros aluden a cierta catalogación de las ciudadanías realmente existentes, mientras las segundas se refieren más bien a las ciudadanías imaginadas. (LOPEZ, 1997, p. 79)

El enfoque de ciudadanía imaginada que postulamos aquí recoge la tesis de comunidades imaginadas de Anderson (1991) sobre el concepto de nación. Al respecto Anderson (1991, p. 23) afirma que una nación es "una comunidad políticamente imaginada como inherentemente limitada y soberana". Basa su argumento en que:

aún los miembros de la nación más pequeña no conocerán jamás a la mayoría de sus compatriotas, no los verán ni oirán siquiera hablar de ellos, pero en la mente de cada uno vive la imagen de su comunión. (ANDERSON, 1991, p. 23).

En este caso la imagen mental o la imaginación de la existencia de una comunidad de iguales (similar a los postulados de Marshall) dan sustento a una nación que se imagina a sí misma limitada, soberana y comunitarista (ANDERSON, 1991). Los factores que dan surgimiento a este fenómeno son la convergencia del capitalismo impreso y la fijación de las lenguas impresas, que genera lenguas de poder, y el consiguiente nacimiento de las lenguas vernáculas administrativas, así como la emergencia de nuevas identidades a las que llama criollos, todo esto en el marco de un contexto de reforma europea.

Ahora bien, para hablar de ciudadanía imaginada es preciso revisar algunos elementos subyacentes a ella. En principio esperamos demostrar, en primer lugar, que una ciudadanía imaginada requiere una zona de contacto para manifestarse. Esta zona de contacto al ser un espacio de relación colonial genera condiciones de hegemonía y dominio. En segundo lugar, siguiendo el raciocinio de Anderson, la lengua configura un factor de identidad y pertenencia, por lo tanto, de diferenciación social. Este hecho hace suponer que la incorporación de 
lenguas orales a estructuras rígidas y formales del Estado, con una lengua impresa y, por esto, con poder oficial, solo será posible en condiciones de subordinación. En tercer lugar, y no menos importante, es la persistencia del sistema capitalista de producción que construye en torno a él imágenes de una sociedad deseable. Finalmente, en cuarto lugar, tenemos la autopercepción de una comunidad que se imagina a sí misma escuchada e incluida a pesar de que la realidad le demuestra persistentemente lo contrario.

De esta manera, la existencia de una zona de contacto, con hegemonía de una lengua impresa y sostenida por un esquema capitalista de producción, va a configurar una ciudadanía imaginada, es decir, un ciudadanía no real, que se mueve en estructuras sutiles de poder imperceptibles, que se imagina incorporada pero que, envuelta en el entrampamiento burocrático estatal, como el caso de los presupuestos participativos, solo puede existir en condiciones de subordinación y marginación.

La ciudadanía imaginada tiene las mismas prerrogativas y derechos que las diferentes concepciones de ciudadanías analizadas. Sin embargo, el acceso a ellos es siempre restringido (como los derechos de educación intercultural o consulta previa) e insustancial (como los derechos territoriales o justicia comunitaria). De ahí que cuando se piensa en una ciudadanía activa en los pueblos indígenas se imaginan modelos de participación ideales. Ahora bien, ¿qué hace que un individuo o colectivo participe políticamente? Franco (1981) considera que detrás de una acción participativa existe un percepción de problemas por resolver y por lo tanto imágenes de una sociedad deseable. Las valoraciones y creencias en torno a la sociedad deseable influyen en la valoración de la participación del individuo. De este modo, el comportamiento político participativo estaría determinado por: 1) imagen de la sociedad deseable; 2) las metas u objetivos sociopolíticos; 3) percepciones y creencias sobre la situación política actual; y 4) valoración que el sujeto realiza de su compromiso personal y de sus consecuencias.

En el marco del presupuesto participativo implementado en la Selva Central del Perú la ciudadanía imaginada se alimenta de imágenes de una sociedad deseable, con una participación aparente, porque no logran romper con la hegemonía de las estructuras dominantes, razón por la que sus demandas sociales no atendidas a veces son canalizadas a través de mecanismos no formales.

\section{PRIMERAS APROXIMACIONES}

Cuando se revisan las bases teóricas que sustentan el presupuesto participativo en el Perú se encuentra que existen una serie de supuestos que no 
toma en cuenta la multiculturalidad social presente. Su configuración asume la existencia de una sociedad de iguales y, por lo mismo, invisibiliza las diferencias, asumiendo también que al ser un espacio de diálogo democrático y "horizontal" todos están en las mismas condiciones de ser parte de él.

En contextos diferenciados, sin embargo, esta sociedad de iguales no existe. La ocupación de la selva alta en La Merced, Satipo y Oxapampa, por ejemplo, despojó a las poblaciones indígenas de sus territorios, reduciéndolas a espacios comunales de supervivencia y alterando sustancialmente sus formas de vida. La "incursión de la modernidad" con agricultura, minería, petróleo, carreteras, entre otros, se materializa en ellos como atraso y pobreza. Con la agresiva actividad antrópica sobre sus ecosistemas desaparecieron sus recursos y, por tanto, sus formas de subsistencia. Poblaciones antes libres y dueñas de territorios y recursos son ahora pequeños grupos marginales que engrosan los niveles de pobreza, empujados hacia una racionalidad del mercado, que no conocen ni entienden, salvo en sus formas más primarias.

Es natural, por eso, ver en este escenario la existencia de diversas representaciones en pugna -cuando se trata del presupuesto participativo- que nos habla de una pluralidad de intereses en juego: clubes de madres, asociación de padres de familia, productores, jóvenes; frentes de defensa, comunidades indígenas, colegios profesionales, instituciones educativas, entre otros, son una muestra de ello. Sin embargo, la confrontación menos perceptible y más persistente es la que se da entre los grupos de colonos migrantes y la población indígena.

En esta lucha por el poder interpretativo los grupos de migrantes y colonos tienen la ventaja de estar más y mejor insertados en la lógica civilizadora de la sociedad y, por lo tanto, ejercen su hegemonía a partir de la posición que ocupan socialmente. Los pueblos indígenas en este escenario estructuran dos discursos en cierta medida opuestos. Por un lado, al saberse excluidos y al margen de la decisiones, responden afirmando sus fronteras y reproduciendo casi autárquicamente su cultura. Por otro lado, al verse incorporados (la cuota indígena, la legitimidad que proporcionan en proyectos de inversión o ser beneficiarios de algunos programas sociales) se imaginan escuchados, atendidos, incluidos, se imaginan ciudadanos.

En el marco del presupuesto participativo, sin embargo, existen suficientes razones para suponer que esta inclusión es aparente. Los principios sobre los que sustentamos la ciudadanía imaginada se materializa en el conflicto intercultural, donde el proceso se realiza bajo el criterio de homogeneidad, se invisibilizan las diferencias y se asume que está compuesto por una comunidad de ciudadanos 
iguales, con predominio de la lengua letrada porque toda comunicación se basa en textos escritos (la oralidad comunitaria no se toma en cuenta), en español (no hay traducción) y con una programación que no se ajusta a los tiempos y características de la población indígena.

También se observa el dominio de la abstracción, porque todo el proceso y las etapas y sub etapas que lo componen necesitan ser analizadas en detalle, requieren de mucha capacidad de abstracción (como ideas de planes futuros, posibilidades de ejecución, criterios de priorización) y de un conocimiento previo del funcionamiento de las estructuras del Estado y el mecanismo de funcionamiento del presupuesto participativo, situación que no se observa en los líderes indígenas. Por otro lado, la organización del presupuesto público, su distribución, formas de ejecución, entre otros, son conocimientos previos poco accesibles e incompresibles para la población indígena.

Resulta relevante también la imposibilidad económica a la que se someten los pueblos indígenas en el presupuesto participativo. La priorización de un proyecto pasa por valorar positivamente el expediente técnico que lo sustenta. Este documento solo puede ser realizado por un equipo de especialistas, habilitados y colegiados, por cuyo trabajo cobran una cantidad de dinero (un porcentaje del presupuesto total de la obra). La población indígena carece de recursos para financiar un documento de esta naturaleza, por lo que se limitan a proponer ideas de proyectos.

Finalmente, observamos una confrontación simbólica a partir de las percepciones sobre la participación. Desde la perspectiva indígena está basada fundamentalmente en la deliberación (intercambio de ideas), la reciprocidad y en criterios de equidad (que las decisiones beneficien a todos). Desde la concepción del colono migrante la participación se basa principalmente en la confrontación (poder y hegemonía), en el dominio del número y en la argumentación.

Se observa, además, en los representantes indígenas una percepción sobre dimensionada acerca de los resultados que esperan alcanzar. En principio asumen que el gobierno local maneja la misma lógica de necesidades por atender y prioridades que ellos; suponen también que la municipalidad atenderá sus demandas y pondrá sus cuadros técnicos y profesionales a disposición para que los ayuden en el diseño de sus expedientes técnicos, lo cual en la mayoría de situaciones no ocurre.

En la lógica participativa de los pueblos indígenas cada proceso de presupuesto participativo es diferente y aislado de los demás, por lo tanto no existe una reproducción de lecciones aprendidas, sino un estado de aprendizaje permanente. Cada representante que participa por primera vez lo hace siempre 
en condiciones de incertidumbre; una situación que viene repitiéndose en los últimos 10 años. Además de eso es importante destacar que las diferentes representaciones indígenas participan de manera fragmentada y dispersa y en competencia entre sí por lograr pequeños proyectos (loza deportiva multiusos, local comunal, botiquín comunal, entre otros) que abonan poco a la lógica del buen vivir.

\section{CONSIDERACIONES FINALES}

La experiencia analizada se ubica en tres distritos de la Selva Central peruana, una zona ancestralmente ocupada por los pueblos indígenas del grupo lingüístico Arawak, siendo el pueblo Ashaninka el más numeroso y el que ha conducido los procesos de resistencia e incorporación a la vida nacional. Tradicionales dueños de estas tierras, los pueblos indígenas se vieron despojados por los procesos de colonización y ocupación ocurridos en diversos periodos históricos, hasta quedar confinados en pequeños espacios territoriales, provocando alteraciones en sus mundos de vida y sin recursos para subsistir. Este espacio regional, entendido como zona de contacto, se caracteriza por las relaciones coloniales y de dominio que se establecen en ella, donde los grupos de colonos migrantes se apropiaron de las estructuras sociales, económicas y políticas para detentar la hegemonía local y dominar a los pueblos indígenas.

En este contexto la democracia liberal implementa el presupuesto participativo, bajo el supuesto que la población toma decisiones de manera libre y en igualdad de condiciones, sin reparar que el presupuesto participativo implica para la ciudadanía un nivel de organización, así como el desarrollo de la capacidad argumentativa y la construcción de redes de poder. En contextos diferenciados el ejercicio de la ciudadanía se torna más complejo por la serie de imaginarios y sensibilidades en juego. Por esa razón, desde su implementación, el presupuesto participativo se ha constituido como espacio donde el peso de las decisiones recae en los grupos locales de colonos migrantes. Los pueblos indígenas, cuyo peso específico en el escenario político no es relevante, difícilmente son escuchados.

Diversas construcciones teóricas intentaron responder a la cuestión de cuál sería la mejor forma de ejercer la ciudadanía en contextos diferenciados. Kymlicka (1996), desde la perspectiva de ciudadanía multicultural, y Yung (2000), desde la perspectiva de la ciudadanía diferenciada, enfatizaron en la necesidad de proporcionar derechos adicionales o colectivos para lograr la incorporación de los grupos subalternos a la vida social plena. Estas propuestas tienen limitaciones cuando hablamos de ciudadanía indígena, pues esta busca la refundación del 
Estado y del sistema social en general y para sus demandas de incorporación transitan indistintamente entre la ciudadanía individual y colectiva.

Esta realidad nos lleva a afirmar que la ciudadanía indígena tampoco es la respuesta a las demandas de los pueblos originarios. Por el contrario, en espacios locales como la Selva Central, configurada como zona de contacto, con relaciones sociales basadas en hegemonía y dominación, lo que se observa es la presencia de una ciudadanía imaginada. Las condiciones para la presencia de una ciudadanía imaginada, recogiendo los postulados de Anderson (1991), se dan en una zona de contacto donde existe una lucha por el poder interpretativo y la producción de significados, la configuración de una lengua impresa con poder oficial y un sistema de producción capitalista que crea la percepción de una sociedad deseable orientada al progreso y desarrollo. Con estas condiciones presentes la ciudadanía imaginada es aquella que transita por estructuras de poder que no puede modificar y se ejerce en condiciones de subordinación y marginación.

La ciudadanía imaginada presente en el presupuesto participativo se materializa en el conflicto cultural persistente entre los grupos en pugna, el dominio del pensamiento abstracto, la imposibilidad económica para los pueblos indígenas y la confrontación simbólica. La presencia de estos elementos no genera mecanismos de resistencia en el sector indígena. Al contrario, al carecer de estrategias de participación, se incorporan al presupuesto participativo generalmente reeditando los errores, en confrontación entre sí y con claro desconocimiento de los logros que pueden lograr con su participación.

Por esa razón, la participación de los pueblos indígenas en el presupuesto participativo no es relevante, porque, además de las razones expuestas, debe lidiar con grupos de migrantes que cuentan con todas las herramientas para hacerse escuchar y, en segundo lugar, deben insertarse y disputar imaginarios en un contexto que conocen y entienden poco. Se observa así que, con serios problemas en el ejercicio pleno de su ciudadanía, con factores implícitos de discriminación por su participación en los espacios de decisión y con capacidades disminuidas para el ejercicio ciudadano, los pueblos indígenas de la Selva Central construyen una ciudadanía imaginada que crea una falsa percepción de inclusión y los deja al margen de los beneficios del presupuesto público.

\section{REFERENCIAS}

ANDERSON, B.. Comunidades imaginadas. Reflexiones sobre el origen y la difusión del nacionalismo. México: Fondo de Cultura Económica, 1993. 
ALONSO, C. Participación Comunitaria e Incidencia Política. Guatemala: UVG, Fundación Soros de Guatemala, 2007. (Colección Manuales de Buenas Prácticas).

CANCLINI, N. G. Consumidores y ciudadanos: conflictos culturales de la globalización. México: Grijalbo, 1995.

FRANCO, C. La preferencia por una sociedad participativa: una exploración en personalidad, ocupación e ideología. En: LANGTON, Kenneth; SCURRAH, Martin; FRANCO, Carlos. Personalidad, poder y participación. Lima: CEDEP, 1981. p. 161-275

GARZÓN, P. Multiculturalismo, ciudadanía y derechos indígenas: hacia una concepción decolonial de la ciudadanía indígena. Tesis Doctoral. Madrid: Universidad Carlos III de Madrid, 2012.

GASCHÉ, J.; VELA, N. Sociedad Bosquesina. Tomo II, Iquitos: IIAP, 2012.

GRAMSCI, A. Prison Notebooks: Rethinking Marxism, Letter 18, 1, 2006, pp. 1-7.

GOW, P. Piro, Apuriña, and Campa: Social Dissimilation and Assimilation as Historical Processes in Southwestern Amazonia. En: D. HILL, Jonathan; SANTOS-GRANERO, Fernando (Ed.). Comparative Arawakan Histories: Rethinking Language Family and Cultura Area in Amazonia. United States of America: University Illinois, 2002. p.147 - 170.

INSTITUTO NACIONAL DE ESTADÍSTICA E INFORMÁTICA. Resultados definitivos de comunidades indígenas. Censos Nacionales 2007: XI de Población y VI de Vivienda. Tomo 3. Lima, 2008.

Mapa de Pobreza Provincial y Distrital 2009: El enfoque de la pobreza monetaria. Lima, 2009

KYMLICKA, W. Ciudadanía Multicultural. España: PAIDOS, 1996.

LIEBERHER, F. El presupuesto participativo: herramienta de una democracia participativa. Urbanews, n. 7, DDC, 2003. p. 1-3.

LOPEZ JIMÉNEZ, S. Ciudadanos reales e imaginarios. Concepciones, desarrollo y mapas de la ciudadanía en el Perú. Lima: Instituto de Diálogo y Propuestas, 1997.

MARSHALL, T. H. Ciudadanía y Clase social. En MARSHALL, T. H.; BOTTORMORE, Tom. Ciudanía y Clase Social. Alianza Editorial, 1998. 
MAT'T, F; ORTA-MARTÍNEZ, M.A second hydrocarbon boom threatens the Peruvian Amazon: trends, projections, and policy Implications. Enviromental Research Letters. IOP Science. V. 5, 2010. Disponible en <http://iopscience. iop.org/1748-9326/5/1/014012>. Acceso: 8 feb. 2015.

MINISTERIO DE EDUCACIÓN. Resultados de la Evaluación Censal de Estudiantes 2014: Presentación de resultados. Lima, 2014.

MOUFFE, C. El retorno de lo político: Comunidad, ciudadanía, pluralismo, democracia radical. Traducción de Marco Aurelio Galmarini, España: PAIDOS, 1999.

ORGANIZACIÓN DE LOS ESTADOS AMERICANOS. Estudios de Casos de Manejo Ambiental: Desarrollo Integrado de un Área en los Trópicos Húmedos-Selva Central del Perú. Washington: OEA, 1987

PERU. Ley No 27783, del 17 de julio de 2002. Ley de Bases de la Descentralización. En Compendio de Normas. Descentralización y buen gobierno. Lima, Defensoría del Pueblo, 2010. p. 30-83.

PERU. Ley No 28056, del 7 de agosto de 2003. Ley Marco del Presupuesto Participativo. En Compendio de Normas. Descentralización y buen gobierno. Lima, Defensoría del Pueblo, 2010. p. 601-609.

PERU. Ley No 27972, del 26 de mayo de 2003. Ley Orgánica de Municipalidades. En Compendio de Normas. Descentralización y buen gobierno. Lima, Defensoría del Pueblo, 2010. p. 174-309.

PRATT, M. L. Apocalipsis en los Andes: zonas de contacto y lucha por el poder interpretativo. Disponible en: < http:/ / www.cholonautas.edu.pe/modulo/ upload/Pratt.pdf> Acceso: 20 de jun. 2015.

POULANTZAS, N. Poder político e classes sociais. Trad. de Francisco Silva, Brasil: Livraria Martins Fontes Editora, 1977.

PRODESCENTRALIZACION. Guía del Presupuesto Participativo Basado en Resultados, Lima, Prodes 2010.

PRUD'HOMME, J. Consulta popular y democracia directa. México: Instituto Federal Electoral, 2001.

PUEBLO WAMPIS conforma primer gobierno autónomo indígena del Perú. Servindi, 30 nov. 2015. Disponible en:< http://www.servindi.org/ actualidad/144577> Acceso en: 12 mayo del 2016. 
RENARD-CASEVITZ, France-Marie. Bibliografía Regional: Los Campa de la Selva Central y Sur del Perú. Redial, París, n. 6-7, p. 148-213, 1995-1996.

RIVET, P.; TASTEVIN, P. Constantine. Les lengues du Purus, Jurua et das regiones limitrophes: le group pré-andin. En: Antropos, France, no 18-19, p. 106-112, 1924.

SANTOS-GRANERO, F.; BARCLAY, F. Amazonía 1940-1990. E1 extravío de una ilusión. Lima: CIAP, CISEPA, 1993.

Órdenes y desordenes en la Selva Central: Historia y economía de un espacio regional. Lima: IFEA, IEP, FLACSO Ecuador, 1980.

SMITH CHASE, R. The Anuesha People of Central Peru: Their Struggle to Survive. Copenhagen: IWGIA, 1974. Mecanografiado.

TANAKA, M. Los tres principios de la participación: involucramiento colectivo, intermediación y pluralismo. Participación popular en las políticas sociales y los grados de complejidad social. Informe final. Lima: IEP, CIES, 2000.

VARESSE, S. La sal de los Cerros. Lima: Fondo Editorial del Congreso del Perú, 2006.

VIERIA, M. La ciudadanía incompleta: Derechos económicos y sociales en la periferia urbana de Brasil. España: Ediciones Universidad de Salamanca, 2014. (Colección Vítor).

WEBER, M. Economía y sociedad: Esbozo de sociología comprensiva. Traducción de José Medina Echevarría et al. $2^{\circ}$ ed. España: Fondo de Cultura Económica, 2002.

YOUNG, I. M. Representação política, identidade e minorias. Lua Nova, São Paulo, n. 67, p. 139-190, 2006. 